\title{
Competitions in Architecture and Urban Design
}

\author{
Miguel Baudizzone \\ Architect; professor, University of Buenos Aires, Argentina.
}

\begin{abstract}
As a partner in Baudizzone - Lestard y Arquitectos Associados, one of Latin America's top architecture firms, the author has been involved in all kinds of projects from buildings to urban parks to urban districts, including the important 180-acre redevelopment plan for Retiro, a historic station and railyards in central Buenos Aires. In this article Miguel discusses the importance of competitions in encouraging fresh views and outside-the-box thinking.
\end{abstract}

\begin{abstract}
A competition is a wonderful opportunity for urban and architectural research. The winner of a competition is the one who has given much more than the "better solution" to a program. The first prize goes for the project that is successful in finding the ideas which, within the given difficulties of the competition brief, appear to be transforming challenges into opportunities for innovation. Of course, as well as being a chance to develop ideas, a competition is a way that a firm has to look for a new job. Without any doubt the most interesting contracts for our office have come to of our drawing boards and computers through competitions.
\end{abstract}

A competition may be considered to be a design investigation. Why? Because proposals are based in memory and discovery: memory as cultural values, including of course the history of architecture and design precedents but also the recovering of personal experiences. Valuing memory means neither to copy what came before nor to try to produce a monument to your own feelings. It means re-invigorating the wider scope of experience, making it part of the future. But this approach is not enough since you need to produce something more, finding it within the program and the competition brief.

Discovering these hidden and non-written parameters gives you the key to creating a new way of interpreting and using that program, building a new geography for a place, adding a new landmark to the city. Next, I will describe two interesting examples from my firm Baudizzone - Lestard y Arquitectos Associados experience.

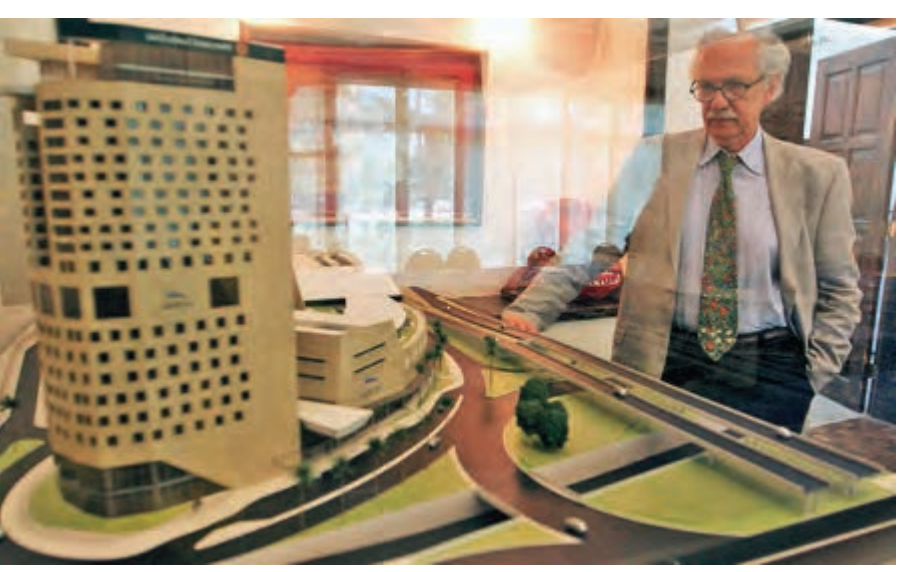

Top: Miguel Baudizzone looking at the model one of his projects. Right: Model for the redevelopment of Retiro central train station and rail yards in Buenos Aires.

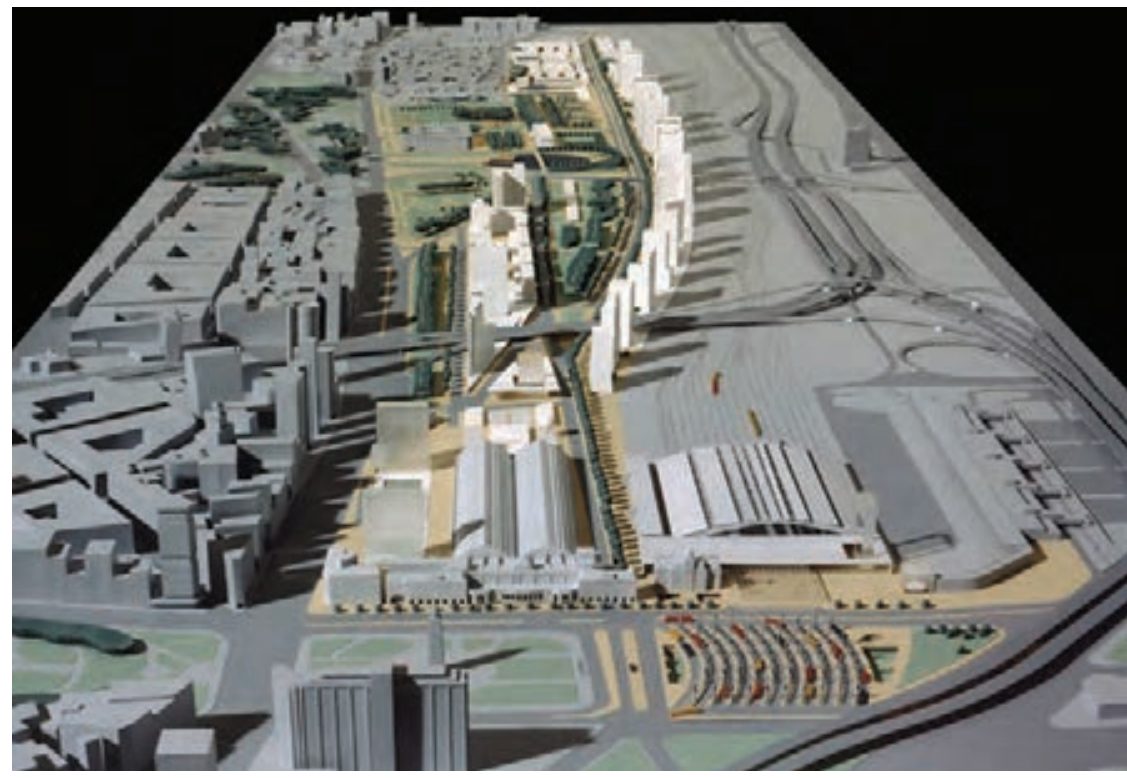

\footnotetext{
${ }^{1}$ For a view of the work by Baudizzone - Lestard y Arquitectos
} Associados go to <http://www.baudizzone-lestard.com/> 


\section{Buenos Aires University Park}

On the bank of the Rio de la Plata, Buenos Aires University Park was designed in honor of the victims of State terrorism, and was awarded first prize at a national architectural competition (associated with architect Alberto Varas) in 1999. This 96-acre park is already built and was designed with two distinct areas. The first one is in an island that was preserved in its original natural state, with its bushes and trees growing from the silt. To maintain its natural character only some necessary protection against water erosion and a few elevated decks for occasional visitors have been added.

The park's major area was designed to honor the victims of the Argentinian military dictatorship ${ }^{2}$ and the victims of the 1994 bombing of the Argentine Israelite Mutual Association headquarters in Buenos Aires where eighty five people died. A strong reminder of a terrible time in our social memory. The site was gained from the river by using precast piling and filling it in with the debris from the bombed building.

The design of the Memorial Park follows a semi-circular abstract plan that continues the Rio de la Plata's waterfront. From a riverside avenue you enter the park through a plaza, a patchwork of grass and stone that in some ways resembles a cemetery. You then arrive at a ceremonial platform designed for speeches and public assemblies. At this point starts a series of walls made of stones engraved with the names of each of the 30,000 people who disappeared during the dictatorship and their age when they were kidnapped. As a bloody scar, the walls zigzag along a processional path across a large bare lawn on a very gentle slope towards the La Plata River.
Selected through a specific competition, several sculptures are scattered in the park. At the end of the path, an impressive human figure sculpture is set in the river and sometimes gets covered by the water, a reminder of the victims who were thrown alive from flying planes by the military. ${ }^{3}$ This dynamic image seasonally bathed by the fresh water provides hope and respect to relatives of the victims and visitors. At this point you look at the endless river, and you meet the waterfront pathway that follows the area circular shape and provides exciting perspectives of the city, under the buzzing movement of the nearby airport.



Illustrative site plan of the University Park with the part on the left taking the original island (top), and the semi-circular area on the right dedicated to the Memorial Park.

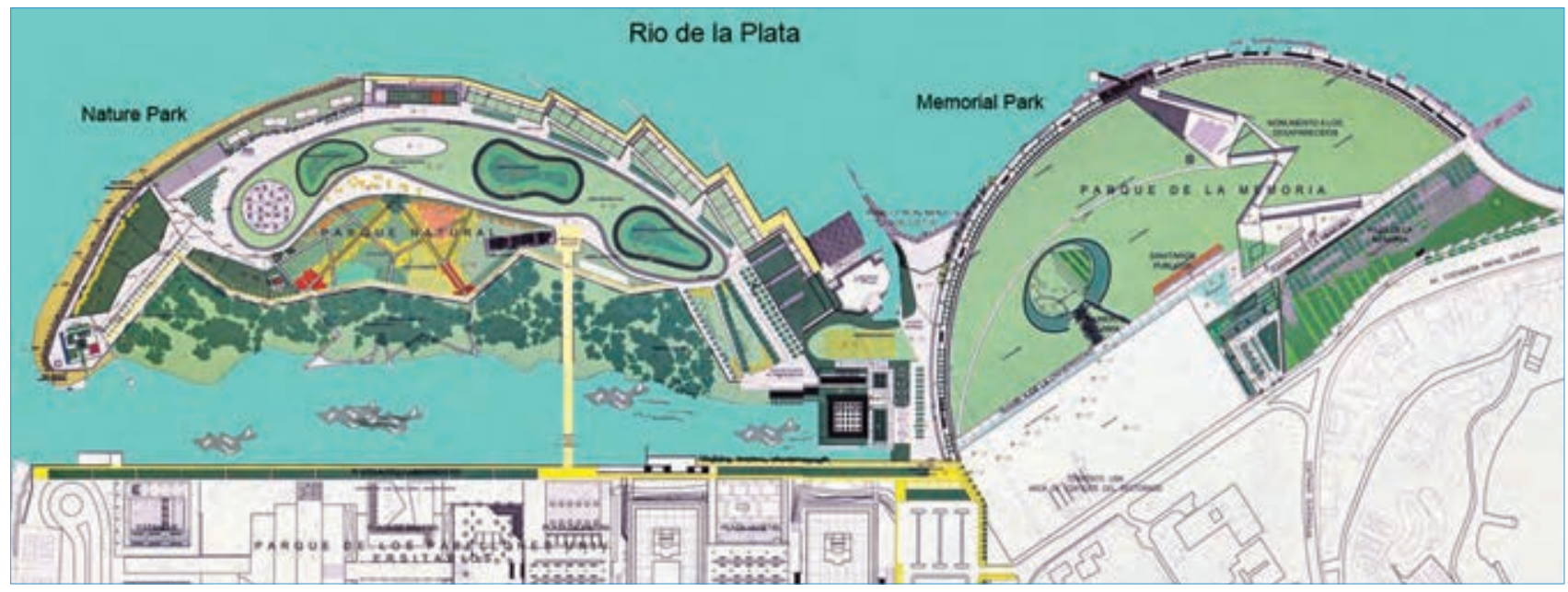

${ }^{2}$ Argentina was ruled by a ruthless military dictatorship from 1966 to 1973 and 1976 to 1983, perhaps the most repressive in South America and responsible for the disappearance of more than 30,000 people from 1976 to 1983 alone.

${ }^{3} \mathrm{~A}$ method used by the military dictatorship to make their opponents and political prisoners "disappear". 

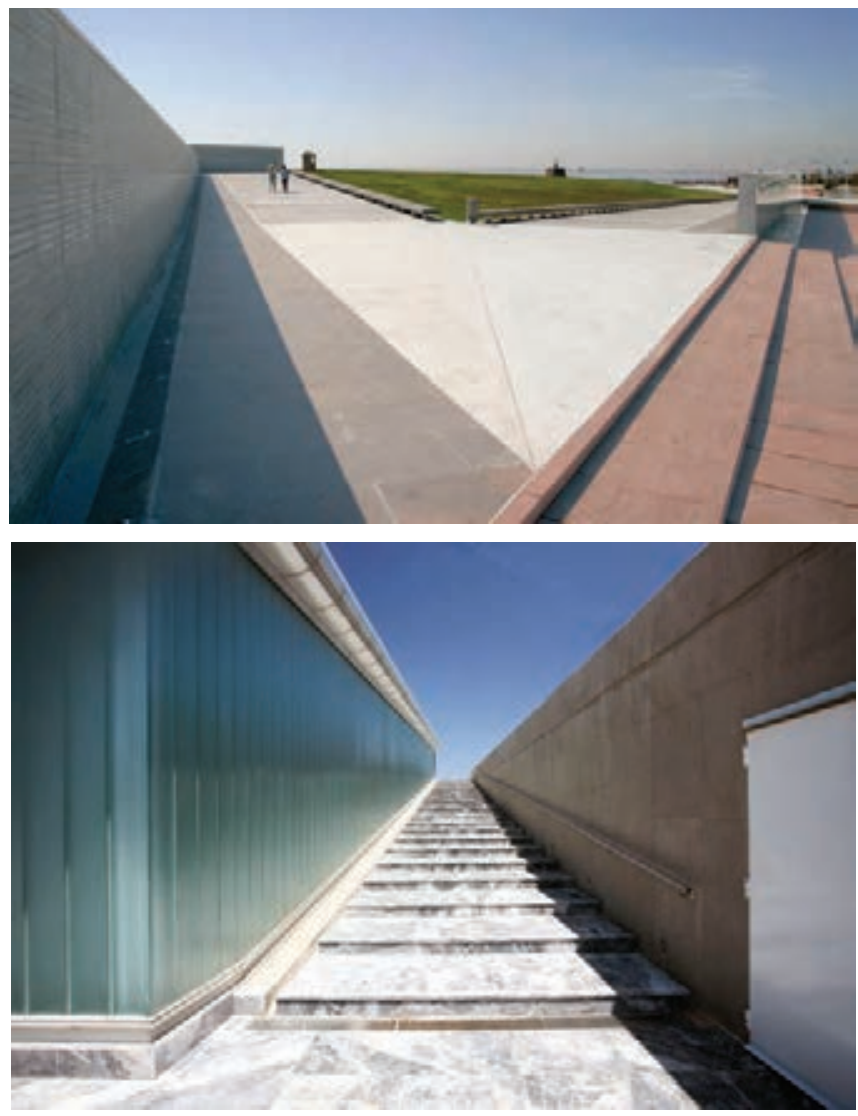

Photos showing the zig-zagging wall with its inscriptions, the long vistas, and the monument building in the Memorial Park.
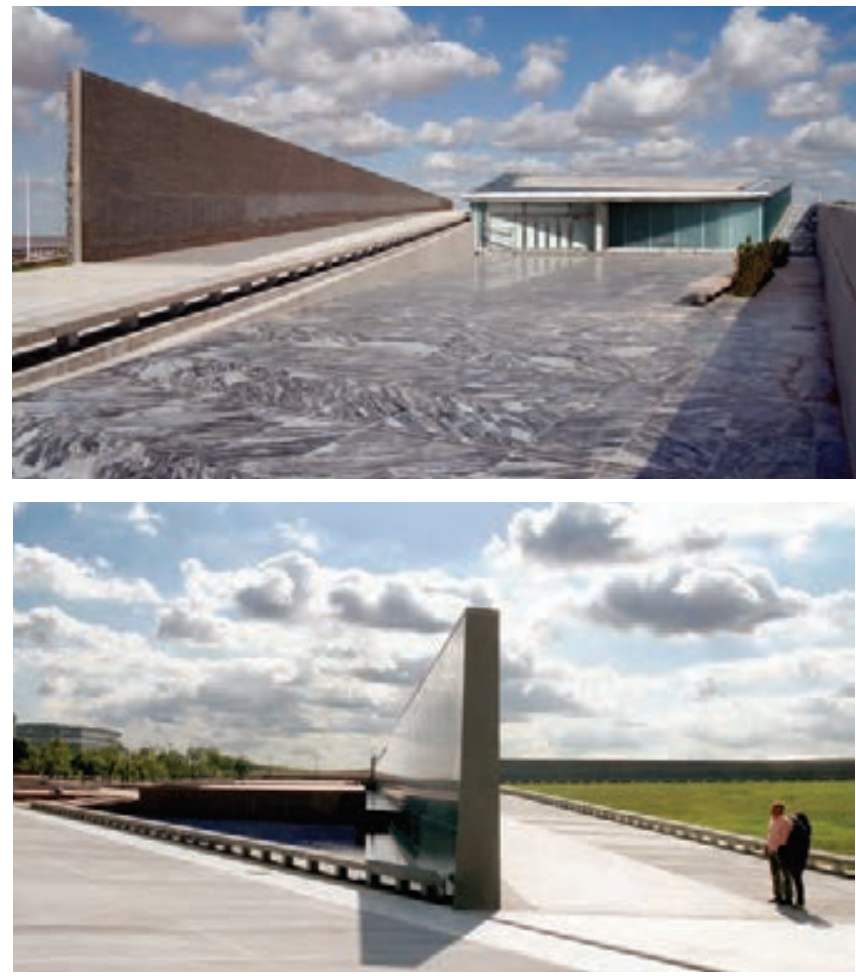

\section{Centre of Technology and Science in Beijing, China}

Our latest win came in the 2012 competition for the Centre of Technology and Science in Beijing, a project in association with KLM Architects and BIAD. Our project includes expanding an existing lake and placing the centre inside a perfectly circular artificial island, elevated from the water level and connected by a series of pedestrian bridges to the surrounding park. The top of the island is a large plaza from where several translucent structures emerge letting light into the underground functions and large lobbies. Visitors wander through this artificial landscape of gardens and light towards an iconic taller building where the main entrance to the underground functions is located. Around the perimeter of this elevated circular island a curtain of water cascades into the lake and composes its main "façade". The sunken building saves energy for a program that needs no windows; covering part of the roof-plaza with gardens and water is also protects against the hard winters and even harder summers.

We like to think the Centre of Technology and Science as a new link of a chain of projects starting in 1972 with our proposal for the Buenos Aires Auditorium, the first competition that we won. This project offered the opportunity to explore the idea of a public space crossing through a private one without trespassing on the exclusive areas. The Chinese public plaza allowed us to revive exactly the same idea but in a completely different location and program. Twenty years later we won another competition using the idea of the circular plan for the Auditorium of the Argentinian city of Mendoza. In this case the geometry was a way of making the building independent from its surroundings. In the Beijing project, on the other hand, the circle is a reference to abstraction (science and technology) in the middle of nature, but also to a shape frequently present in Chinese traditional architecture. Once again, memory and discovery, nature and abstraction, existing and new landscapes; a program envisioned as a building was made invisible by its transformation into an island.

The model for the Buenos Aires Museum, an inspiration for the competition in China.

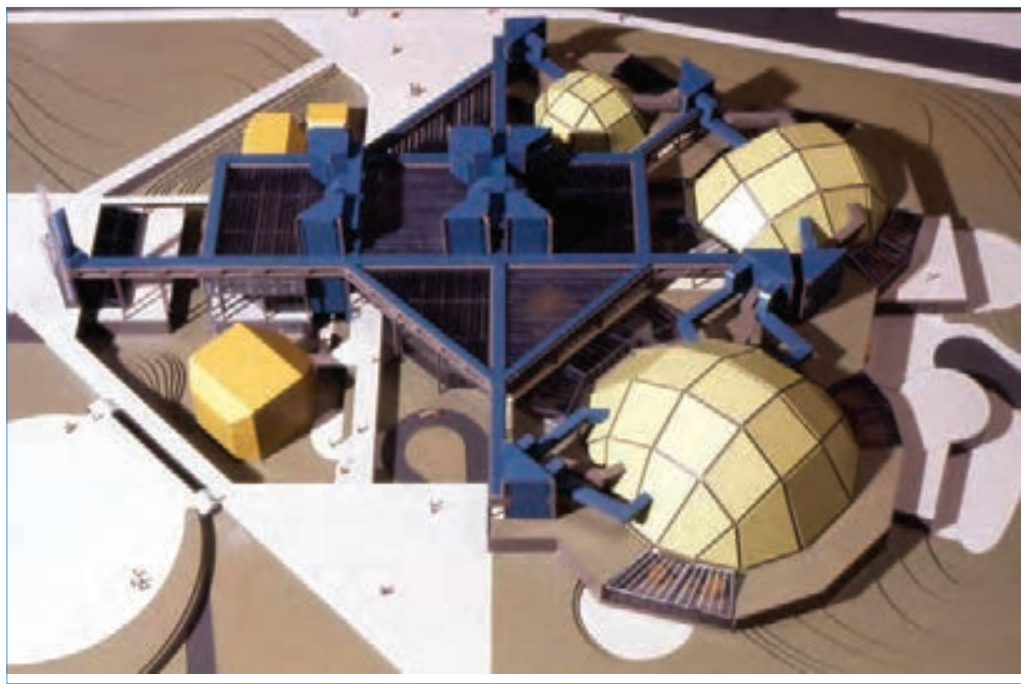


Our firm has won a dozen first prizes, but we have submitted proposals for more than a hundred competitions with varying degrees of success. But in every instance we have tried to find something new, to make architectural and urban design ideas clearer for us, to think about each context, the meaning of design and the possibilities of each material.
The secret is to discover the special conditions of each challenge, even if it is accused of eclecticism by the design intelligentzia. Of course, to participate and be successful in public competitions you will always need a lot of effort, a huge dose of inspiration, and a good team of consultants. And last but not least, you also need a little luck...

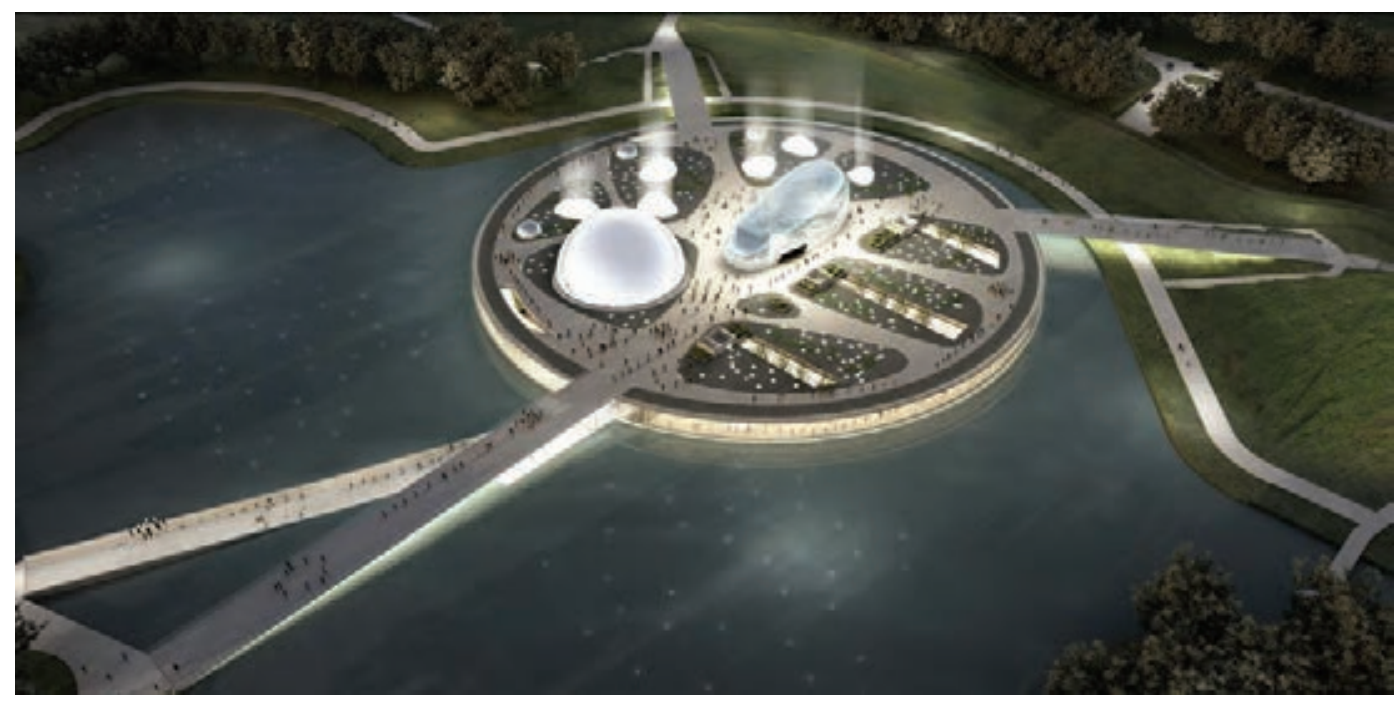

Images of the winning entry for the Center of Technology and Science in Beijing, China. The artificial island is connected to the surrounding park by bridges and the building's facade is composed of a waterfall. Skylights illuminated from inside compose the landscaoe design in an engaging atmosphere.
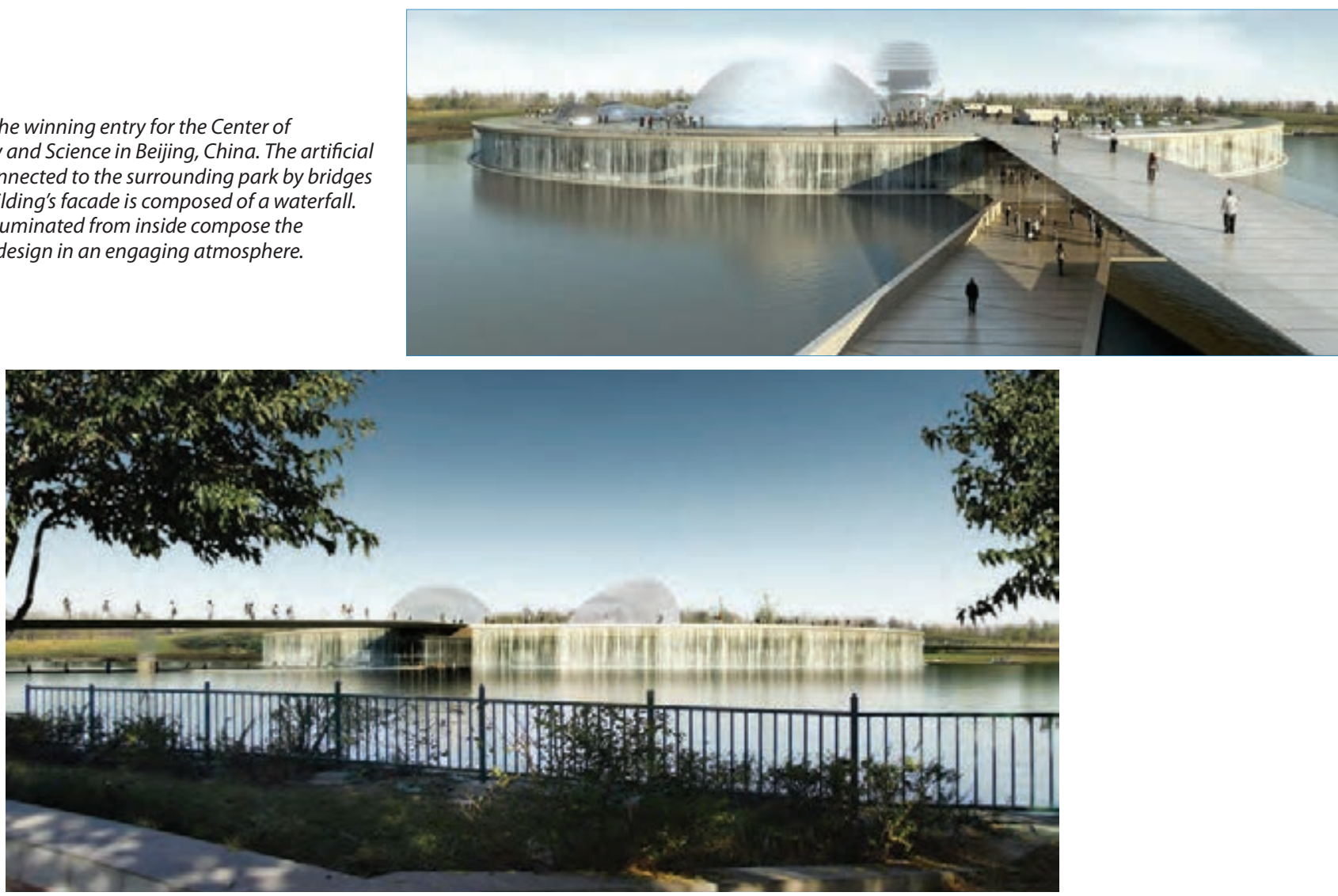